\title{
Are women properly represented in scientific publication and research? Interim results from a Spanish case study in Earth Sciences
}

\author{
${ }^{1}$ Dept. of Geology, Plaza de la Merced s/n, University of Salamanca, 37008 Salamanca, Spain. *Corresponding author E-mail: mdp@usal.es \\ 2 Dept. of Sociology. Campus Tarongers. AvdaTarongers 4B, 46021 Valencia, Spain. E-mail: capitolina.diaz@uv.es
}

(Received 10/03/2015; Accepted 08/07/2015)

DOI:10.18814/epiiugs/2016/v39i1/89237

In 2015 there still are gender disparities in Science. These are reflected in different aspects of science such as the comparatively few major research projects led by women and relatively low numbers of women as authors in major publications (even fewer as first or last author). Much work has been published on this issue, concluding that only around $30 \%$ of science authors are women, and although more research is needed, it is clear that the pipeline from junior to senior positions leaks female scientists. Most decision boards have an exclusive male composition and there is a need to study whether this affects the result of any selection based on the peer-review process. The unbalanced composition includes editorial boards of major journals. This article investigates this and other unbalanced situations to understand the extent to which citation and publication patterns differ between men and women in science in general and in earth sciences in particular, and the negative impacts of some widely used indices that can bias the research output from a gender perspective. We conclude that men are more published and more cited than women due to a number offactors, from the lack of awareness of the value of gender equity to the overwhelming masculine presence on editorial boards and manuscript reviewers and to an overall weak network of female scientists.

\section{Introduction}

The purpose of this paper is two-fold. On the one hand, it intends to demonstrate that the number of publications by women scientists is lower than that of men and consequently women are less cited and have a lower h-index. This is a fact that can jeopardize women's academic careers. On the other hand, we try to reveal the main factors that lead to this state of affairs and to make some suggestions on how to overcome the current disparities between women's research and their publications and citations. We also try to demonstrate that the h-index is more biased than its creator thought.

Limiting the research to Spain and to the discipline of earth sciences, we focus on the h-index due to the impact that it has for the promotion and acknowledgement of scientists and on the ratio between female and male scientists who apply (and are successful) for their first research position and for a research grant. We also compare the tendencies of women and men to cite their colleagues and themselves and its negative effect on women's citations. Malakian et al. (2013) demonstrated that men get cited more than women in the field of International Relations and their results may well serve as a model for studying other fields. Their conclusion illustrates how social and subconscious factors might slow down the advancement of science and its diffusion

There is little general awareness of the disparity between women and men in science although it might be evident. Female students get equal and even better qualifications than their male peers but, internationally, they have more difficulties to obtain employment and, even more, to get a high position (e.g. in geology: Alonso-Zarza et al. 2008). Women scientists do not secure a research grant as easily as male scientists do. Besides that, it is pointed out that some of the databases are not disaggregated by sex, indicating that neither people working with researchers data, nor researchers and education authorities are aware, or may not be interested in knowing, if there is, or there is not, a gender difference in scientific performance.

The research questions prompting this study are:

- Why are fewer women with a high Hirsch Index (h-index) than men in general and in earth science in particular? and

- What can be done to improve this situation in science overall and in earth science specifically?

Possible misuse of the h-index to validate researchers adds up to an unfair situation for women in science that could reduce their chances of progress in a research career, as is demonstrated by the UNESCO Institute for Statistics and many scientific publications to date (Pereira 2014 and references therein). According to this UNESCO study, only $30 \%$ of the world's researchers are women, while most students enrolling at university are women (59\% in 2010, Pereira 2014 and references therein). However, many women drop out at the 
highest levels required for a research career. In general, women do as well as men in getting their PhDs (Table 1, see below), but remain under-represented in Research and Development (R\&D) in every region of the world. Just one in five countries has achieved gender parity with between $45 \%$ to $55 \%$ female researchers. A closer look at the data reveals some surprising exceptions. For example, in Bolivia women account for $63 \%$ of researchers, compared to France with a rate of $26 \%$ or Ethiopia at $8 \%$ (http://www.uis.unesco.org/ ScienceTechnology/Pages/women-in-science-leaky-pipeline-dataviz.aspx). But the h-index seems to be lower for women in all regions. Here, we relate this data to the likely structural gender discrimination of the science system and to the ways in which women communicate their own successful outputs.

\section{The h-index for women scientists}

In 2005, J. E. Hirsch published a highly cited article proposing an index, the h-index, to estimate the importance, significance and broad impact of a scientist regarding his or her cumulative research contributions. The h-index for an author is based on the highest number of papers included that have had at least the same number of citations. Hirsch argued that this serves to characterize the scientific output of a researcher and since then the index is being used to compare competing researchers from the same subject areas for the same resources (e.g. research grant, academic or research position). The author concluded that this was an unbiased measure of publication efficiency. However, when analysing the procedure for extracting the h-index for a group of researchers some caveats have been detected (Leydesdorff, 2008). To determine the h-index of a researcher, several databases can be used, the Web of Science, Scopus and Google Scholar being the most useful. They all differ in the citation work they include. Web of Science (WOS) only takes into account citations counts for articles indexed within its own database, that is, journals with an impact factor recognized by the Journal Citation Report in the WOS. Google Scholar and Scopus count, in addition, contributions in congresses and journals indexed in WOS and other databases. Typing the name, surname, locality etc. in the different fields of the search engine of the database one should be able to obtain the h-index of a specific author. There are some limitations when using the search fields of the databases, though, as authors are not always systematic and consistent in designating the authorship of an article. This is more evident for authors coming from countries where several names and surnames are used (e.g. Spain, Portugal, Brazil and other Latin American countries) and using initials is not a common practice. For this reason an author can be found using different combinations of names and surnames, thereby obtaining a different h-index depending on which name (or surname) is used for a particular publication. This is not always dependent on the author, and mistakes in references can be introduced by the journal editorial as composed names, names with accents, and other naming peculiarities are often difficult to find (Harzing, 2008; Bar-Ilan, 2008). Therefore such publications will not be found in a simple search for the author in WOS and therefore for the author's most valuable h-index. This feature might constrain the securing of comprehensive h-index information and may have affected the data for the h-index we have used for this paper, although we were careful to take this into consideration. In any case, depending on the database used for the search, the same author will be retrieved with a different (sometimes with a very substantially different) hindex (Bar-Ilan, 2008).
An observation related to the use of the h-index to explain efficiency in disseminating science is that it has been demonstrated that women systematically obtain a lower value in all scientific fields, independently of their respective contribution on the subject matter. This means that women are steadily cited less than men, including self-citations (Maliniak et al. 2013). A self-citation is a reference in an article to other work by the author of the article, which is not, in principle, a problem since academics conduct long-term projects and they publish partial results according to the project's progress; it is only natural to refer to earlier work when it is part of the context for a new article (http://curt-rice.com/2013/10/19/the-great-citation-hoaxproof-that-women-are-worse-researchers-than-men/). But women are more reserved about referring to themselves than men are. In fact, Maliniak et al. (2013) found that men cited their own previous work about twice as much as women did. These authors determined whether subtracting self-citations from the totals in the database produced a similar result of citations for men and women, but they found that the gender gap still remains. It turns out that self-citation leads to more citations by others. Through self-citation, colleagues become aware of the work and may refer to it themselves. As citation counts are increasingly used as a key measure of research quality and impact, this affects the h-index for women that then translates into less funding and lower research achievements when this index is used for quality and quantitative comparison of researchers of both genders.

\section{Methodology}

To simplify the work, we have only used data for Spanish female scientists. Several studies show that the number of female scientists in Spain is proportionally comparable to that for North America and Western Europe (Gonzales, 2010; European Commission, 2013; Pereira, 2014 and references therein). For this study we have used the database from Grupo para la Difusión del Índice h (DIH, Group for Widely Diffusion of h-index in English translation) and the report prepared and published by the Ministry of Economy and Competitiveness, through its Unit for Women and Science: Científicas en Cifras 2013 ("Women Scientists in Figures", in English translation). In the latter we have used data for earth scientists applying for a research position, either at the university or at any other public research institution, and data for earth scientists applying to research grants, from 2008 to 2012. From both sets of data we have extracted the number of female scientists applying and obtaining the position (at the lowest research level) and the funding respectively (Tables 2 and 3).

DIH publishes every year the list of Spanish scientists with a high h-index (h-index=10 and above, http://indice-h.webcindario .com/), making the assumption that this index increases with the quality of research, and allows rankings to be established among the best researchers within the same research area. DIH's information comes from the highly prestigious ISI Web of Knowledge database and therefore assumes that the $h$ values obtained are objective and testable. All Spanish public research institutions have access to this database (https://www.accesowok.fecyt.es/). At the moment of writing this paper the DIH database contains a list of over 3784 Spanish researchers from 10 different areas subdivided into 156 different research subareas, each with h-index higher than 10 . The average hindex is 26. It has to be taken into account that some researchers are working in more than one scientific area. In this study we have omitted those duplications (or triplications for some, mainly male, 
researchers) to analyse the general picture (Table 4), but we have kept the numbers for the different subareas of earth sciences (Table 5). The DIH group aims to offer lists of the main researchers from different areas and from different Spanish provinces. It updates the $h$ values periodically for all its lists. Our data comes from the last months of 2014.

Although this study focuses on the results for women in earth sciences, we have included data as well for other scientific disciplines such as mathematics, physics and chemistry that traditionally are part of those subjects that, together with engineering and technological careers (science, technology, engineering and mathematics: STEM), tend not to appeal to nor retain women in large numbers. We also analysed data for biology and health sciences that are supposedly more attractive for female students and researchers than to their male counterparts (Gonzales, 2010; European Commission 2013; Pashkova et al., 2013). In earth sciences the database is divided into subdisciplines: crystallography, geochemistry and geophysics, geography, physical geography, geology, geosciences multidisciplinary, meteorology and atmospheric sciences, mineralogy, mining and mineral processing, palaeontology and water resources. Some of these do not have researchers (either male or female) with h-index listings, but we have kept the information for future research.

The lists are not segregated by sex. To identify female researchers from the lists we took into account the name of the researcher since most Spanish names are not ambiguous in relation to gender, except in a few cases such as researchers from provinces like Catalonia and the Basque Country, as well as some international researchers working in Spanish institutions. When the researcher's sex was doubtful, we used the Internet to determine it through their institutional web pages and performing searches with the use of Google search engine (Jagsi et al. 2006). Therefore it has been possible to disambiguate who was male and who was female.

\section{Results}

Every year the Spanish Ministry of Education, Culture and Sports publishes data for the educational system with indicators for different levels. Data from 2012-2013 show that in Spain 54.3\% of university students are female (Ministerio de Educación, Cultura y Deportes, 2014). This ratio increases to $57.6 \%$ when considering the students finishing their degrees. Subjects related to engineering are dominated by men while health science is dominated by women. This feature has been observed for most education systems all over the world (Pereira, 2014 and references therein). Female students are also in a higher proportion as well when considering masters degrees, with almost the same proportions per subject area as in lower degrees. The total number of graduated students in sciences, including earth sciences, in 2013 was 10,661 of which $52.4 \%$ were women. 4,928 completed a Master program, of which $50.4 \%$ were women and 3,773 ended up with a doctoral degree in sciences, of which $48 \%$ were women. From these numbers we see that $35 \%$ of graduate students decide, and are successful, to complete a doctoral degree in sciences and almost half of them are women. For comparison, Table 1 shows the numbers of PhDs in science, health science and engineering (Ministerio de Educación, Cultura y Deportes, 2014). These will be the researchers competing for grants and publishing their research results in the following years. It is a reasonable assumption that they are equivalent to the researchers we studied for this paper. In Table 1 we included data from 2008 to 2012 to determine the trend in university doctoral studies, both in Europe and Spain, and to compare this data on research funding over the same period.

Spain launches annual specific calls for proposals for basic and applied research funding in public and private institutions, as well as a specific call to contract young researchers to their first research position (both at universities and public research institutions). The call to fund research has two separate call identifiers, since it is addressed to two different groups of researchers: young, emerging researchers and senior ones with a consolidated career. Both should be working already within the public research system. The second call is intended to contract recent $\mathrm{PhDs}$ to continue their research in a specific research area within a prestigious research group in a university or research institution to help to consolidate their research career.

A total of 2,387 researchers were scrutinized in the DIH database for the h-index in the different scientific areas (Table 4, Figure 1). Of the studied areas, those with relatively few female researchers with a high h-index are mathematics, physics and engineering, with less than $5 \%, 10 \%$ and $14 \%$ respectively. Computer science had none. In the remaining areas, the numbers are also not high. The ratio of female researchers with high h-index is around $18 \%$ for earth science and chemistry and around $19 \%$ for biology. It should be noted that although the h-index of women in health science is only $22 \%$ (Table 4 ) the total ratio of women researchers in this field is much higher than that of men. Research undertaken by the Clinic Hospital of Barcelona between 1996 and 2008 found that for some specialities there were 2,077 females to one man. Even with these numbers, only $10 \%$ of female doctors had achieved the highest positions in the hospital versus $29 \%$ of the males (MacPherson, 2015)

Regarding earth science (Table 5, Figure 2), the database contains a total of 224 researchers, of whom 36 are female (around 17\%). To

Table 1. PhDs defended in different scientific areas. EU-27 stands for the Europe of 27 countries. W=women. Source: Spanish Ministry of Education, Culture and Sports (Ministerio de Educación, Cultura y Deportes, 2014)

\begin{tabular}{|c|c|c|c|c|c|c|c|c|c|c|c|c|}
\hline \multirow[t]{4}{*}{ Year } & \multicolumn{12}{|c|}{ Defended PhDs } \\
\hline & \multicolumn{4}{|c|}{ Science } & \multicolumn{4}{|c|}{ Health Science } & \multicolumn{4}{|c|}{ Engineering and Architecture } \\
\hline & \multicolumn{2}{|c|}{ EU-27 } & \multicolumn{2}{|c|}{ Spain } & \multicolumn{2}{|c|}{ EU-27 } & \multicolumn{2}{|c|}{ Spain } & \multicolumn{2}{|c|}{ EU-27 } & \multicolumn{2}{|c|}{ Spain } \\
\hline & Total & $\mathrm{W}$ & Total & $\mathrm{W}$ & Total & $\mathrm{W}$ & Total & $\mathrm{W}$ & Total & $\mathrm{W}$ & Total & $\mathrm{W}$ \\
\hline 2012 & 37635 & $43 \%$ & 3773 & $48 \%$ & 20969 & $59 \%$ & 1512 & $56 \%$ & 18218 & $28 \%$ & 802 & $30 \%$ \\
\hline 2011 & 36414 & $43 \%$ & 3936 & $46 \%$ & 20764 & $57 \%$ & 1204 & $56 \%$ & 17664 & $28 \%$ & 608 & $30 \%$ \\
\hline 2010 & 31577 & $41 \%$ & 2697 & $47 \%$ & 18460 & $56 \%$ & 1086 & $55 \%$ & 14822 & $26 \%$ & 1296 & $34 \%$ \\
\hline 2009 & 30609 & $43 \%$ & 2651 & $51 \%$ & 19323 & $57 \%$ & 964 & $59 \%$ & 14768 & $26 \%$ & 778 & $32 \%$ \\
\hline 2008 & 30523 & $42 \%$ & 2448 & $49 \%$ & 18196 & $55 \%$ & 1075 & $58 \%$ & 13497 & $24 \%$ & 682 & $31 \%$ \\
\hline
\end{tabular}


Table 2. Number of applications and obtained positions out of these applications within the Human Resources National Program, disaggregated by gender, with percentage for female participation in applications and successfulness in obtaining a position at first level of research. Data from Ministerio de Economía y Competitividad, 2014

\begin{tabular}{|c|c|c|c|c|c|c|}
\hline \multirow{2}{*}{ Year } & \multicolumn{5}{|c|}{ Human Resources Program for Earth Sciences } \\
\cline { 2 - 7 } & \multicolumn{3}{|c|}{ Applications } & \multicolumn{3}{c|}{$\begin{array}{c}\text { Obtained positions at } \\
\text { first research level }\end{array}$} \\
\cline { 2 - 7 } & Male & Female & \% Female & Male & Female & $\%$ Female \\
\hline 2008 & 380 & 224 & 37 & 197 & 103 & 34 \\
\hline 2009 & 599 & 470 & 44 & 254 & 133 & 34 \\
\hline 2010 & 561 & 472 & 46 & 171 & 105 & 38 \\
\hline 2011 & 455 & 442 & 49 & 150 & 125 & 45 \\
\hline 2012 & 526 & 622 & 54 & 72 & 72 & 50 \\
\hline
\end{tabular}

Table 3. Number of applications and obtained funding out of these applications within the Research Funding National Program, disaggregated by gender, with percentage for female participation in applications and successfulness in obtaining funding. Data from Ministerio de Economía y Competitividad, 2014

\begin{tabular}{|c|c|c|c|c|c|c|}
\hline \multirow{2}{*}{ Year } & \multicolumn{5}{|c|}{ Research Funding Program for Earth Sciences } \\
\cline { 2 - 7 } & \multicolumn{3}{|c|}{ Applications } & \multicolumn{3}{c|}{$\begin{array}{c}\text { Obtained positions at } \\
\text { first research level }\end{array}$} \\
\cline { 2 - 7 } & Male & Female & \% Female & Male & Female & $\%$ Female \\
\hline 2008 & 1127 & 543 & 32 & 920 & 458 & 33 \\
\hline 2009 & 1359 & 693 & 34 & 1039 & 507 & 33 \\
\hline 2010 & 1273 & 618 & 33 & 865 & 387 & 31 \\
\hline 2011 & 1353 & 730 & 35 & 854 & 459 & 35 \\
\hline 2012 & 1584 & 856 & 35 & 713 & 404 & 36 \\
\hline
\end{tabular}

focus on the publication efficiency of female researchers in earth sciences we analysed data for women accessing opportunities for research positions and grants during five years (from 2008 to 2012) (Tables 2 and 3), because they would be the group of researchers with more opportunities to publish their results in competitive journals that are the journals with an impact factor that counts towards calculation of the h-index.

Table 4. Spanish Group for Widely Diffusion of $h$-index database for all scientific areas. Researchers in the table have an $\mathbf{h}$-index of $\mathbf{1 0}$ or higher

\begin{tabular}{|l|c|c|c|c|}
\hline Scientific area & $\begin{array}{c}\text { Total } \\
\text { Researchers }\end{array}$ & Male & Female & $\begin{array}{c}\% \text { Female } \\
\text { researchers }\end{array}$ \\
\hline Earth Science & 224 & 188 & 36 & $\approx 16$ \\
\hline Mathematics & 74 & 70 & 4 & $\approx 5$ \\
\hline Physics & 256 & 230 & 26 & $\approx 10$ \\
\hline Chemistry & 226 & 186 & 40 & $\approx 18$ \\
\hline Biology & 415 & 336 & 79 & $\approx 19$ \\
\hline Health Science & 646 & 506 & 140 & $\approx 22$ \\
\hline Material Science & 132 & 100 & 32 & $\approx 24$ \\
\hline Engineering & 231 & 199 & 32 & $\approx 14$ \\
\hline Agriculture & 166 & 118 & 48 & $\approx 29$ \\
\hline Computer Science & 17 & 17 & 0 & 0 \\
\hline Total & $\mathbf{2 3 8 7}$ & $\mathbf{1 9 5 0}$ & $\mathbf{4 3 7}$ & $\approx 16$ \\
\hline
\end{tabular}

It should be taken into account that the h-index cannot decrease for a given researcher and consequently it must be considered as an accumulating indicator of lifetime achievement, in the case of individual scholars. Therefore even very productive young researchers, in principle, will have lower chances to have higher h-index than senior very productive researchers. It should be noted that Tables 4 and 5 are dedicated to researchers who have an h-index of 10 or higher and these are probably not representative of the majority of researchers since women who come into that cohort are likely to be the most talented and most assertive, if we take account of their academic results. Therefore the totals might well be unrepresentative, i.e. the position might actually be worse than the tables suggest for those women who do not reach that minimum. Anderson Eloy et al. (2006) found that for specific areas in medicine, male researchers had higher overall research output than women as measured by the $\mathrm{h}$ index, but rates of research productivity varied throughout different career stages. At an early stage men had higher productivity rates, but at the more senior levels women had higher rates and absolute hindex levels. This feature can have implications for academic promotions for female researchers.

\section{Discussion}

Table 1 shows that the number of female $\mathrm{PhDs}$ in science is quite similar to the number of male $\mathrm{PhDs}$ in science in Spain, the former being somewhat higher than the average for Europe. The number of engineering and architecture PhDs in Spain is higher than in Europe as well, but again the percentage of women is lower than for men, as expected (Pereira, 2014). Female students in health science make approximately the same percentage as in Europe, always higher than for male students. At the same time, Spain has a higher number of female researchers (39\%) than the average for North America and Western Europe (32\%) (Source: UNESCO Institute for Statistics, web site last visited 2016-01-26). However, in all areas the number of Spanish female researchers with h-index equal or higher than 10 is worryingly low (average less than $16 \%$, table 4 ) given that the percentage of female researchers gaining a research position in a public institution increased steadily over the studied period (2008-2012), reaching $50 \%$ on the last year (54\% of female researchers applying for a research position in that same year). However, the number of women who were awarded a research grant is much lower (maximum $36 \%$ on the last studied year). Still, this $36 \%$ of women researchers

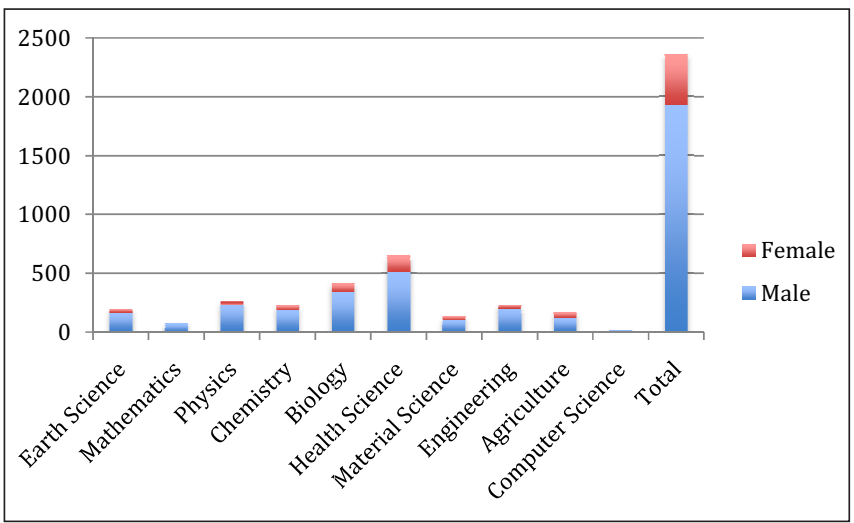

Figure 1. Spanish researchers in all areas of sciences with an $h$ index of 10 or higher. Source of data: Spanish Group for Widely Diffusion of h-index database for earth sciences. 
Table 5. Spanish researchers in the different areas for earth sciences with an h-index of 10 or higher. Source: Spanish Group for Widely Diffusion of h-index database for Earth Sciences.

\begin{tabular}{|l|c|c|c|}
\hline Earth Science & \multicolumn{3}{|c|}{ Researchers with h-index } \\
\hline Subarea & Male & Female & $\%$ Female \\
\hline Crystallography & 17 & 1 & $5.5 \%$ \\
\hline Geochemistry and Geophysics & 42 & 8 & $16 \%$ \\
\hline Geography & 1 & 0 & $0 \%$ \\
\hline Physical Geography & 6 & 0 & $0 \%$ \\
\hline Geology & 6 & 1 & $14 \%$ \\
\hline Geosciences multidisciplinary & 51 & 10 & $16 \%$ \\
\hline Meteorology and Atmospheric Sciences & 26 & 7 & $21 \%$ \\
\hline Mineralogy & 15 & 6 & $29 \%$ \\
\hline Mining and Mineral Processing & 0 & 0 & $0 \%$ \\
\hline Palaeontology & 8 & 1 & $11 \%$ \\
\hline Water Resources & 16 & 2 & $11 \%$ \\
\hline
\end{tabular}

with a grant is much higher than the $16 \%$ in average when considering those having an h-index of 10 or higher. Traditionally "male subjects" such as mathematics, physics and engineering have a very low number of women with h-index in this table. But other subjects where women are more strongly represented (She figures, 2012; Pashkova et al. 2013; Pereira, 2014) do not have a much higher number of female researchers in the database. Even the areas related to health science, where there are more female researchers than men in most countries, including Spain, we find only $22 \%$ of women having a high h-index. If we concentrate on values for earth science, we find that only the subdiscipline of mineralogy has a percentage of women with high hindex closer to the number of female researchers in Spanish science overall (29\% and 39\% respectively).

El-Hinnawi (2015) assesses the scientific productivity in earth and planetary sciences in the world using the number of publications in scientific journals listed in Elsevier's SCOPUS system. The author retrieved data from 32,000 journals in all scientific fields for the period 1996-2012 (http://www.scimagojr.com) on 1st April 2014. Scimago is a Spanish organization specializing in scientific information management (databases, bibliometrics, scientometrics, etc.) that maintains records of the number of publications in different scientific

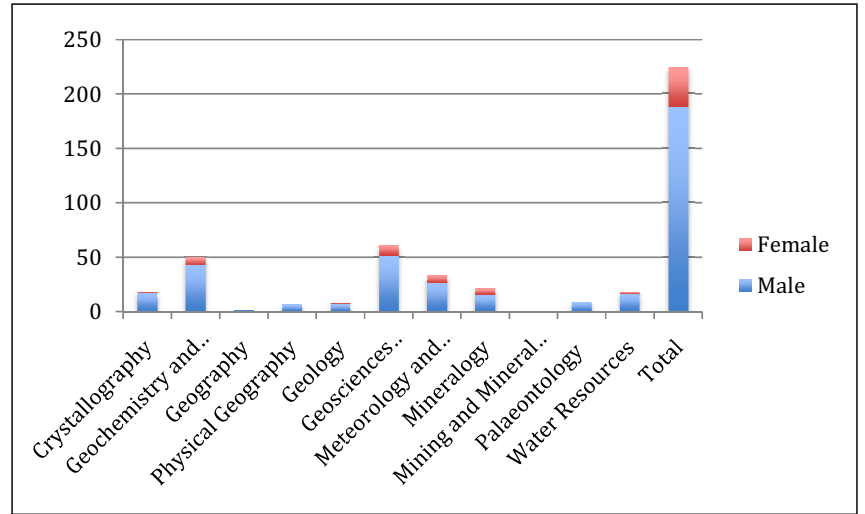

Figure 2. Spanish researchers in earth sciences with an h-index of 10 or higher. Source of data: Spanish Group for Widely Diffusion of h-index database for Earth Sciences. fields, their citations and h-index. Data on the regional distribution of publications and different subdisciplines of earth and planetary sciences were taken into account.

The Western European Region has dominated the output of publications in earth and planetary sciences since 1996. Spain is number 10 in the top 10 list of countries. This could be interpreted as a major high h-index achievement for Spanish researchers, including female researchers. The reality is different, causing the authors of this paper to reflect on the possible reasons. The number of female researchers gaining a research grant is much lower than their male peers. The lack of funding is related to the lack of research and lack of publication of results. Also, this may be affected by the way in which personal and family names are used in Spain. This inevitably affects the publication records of those remaining researchers and the possibilities of success in the next call, perhaps leading to a circle of decline.

Many countries around the word have gender equality laws. Spain has had its own specific legislation since March 2007 (Boletín Oficial del Estado, 2007). The purpose of these laws, regarding the issue under consideration here, is to promote gender equality, including equal integration and equal opportunities in all levels within public institutions, such as universities or public research institutions. This should be reflected in the gender-balanced composition of all selection and promotion boards for academic staff positions and, ultimately, the balance of staff.

Although some improvement has been reached, in many of our institutions the law has not yet been implemented (Pereira, 2014). From the data obtained from the analysis of researchers applying for and obtaining research positions it can be deduced that parity in the composition of committees has increased the chances of female researchers in securing position. In fact, in the studied period there was a, possibly encouraging, increase of female researchers gaining a first stage research position.

Most editorial boards of the highest prestigious journals are composed by almost $100 \%$ male scientists. It is difficult (or even impossible) to collect data related to the gender of manuscript reviewers, but it would be reasonable to deduce that most reviewers are similarly male. Men have more chances for publicising their own research because not only do they seem to publish more than their female peers, but also are likely to be more effective working in networks, including social networks, that are dominated by males (Arenzon et al., 2013). This could affect the number of publications of female researchers adversely, impacting on their publication records and thus become an impediment to competing under equal circumstances when applying for a research grant, as can be seen from Table 3 .

To solve this actual or potential discriminatory situation, many parties should be involved: governments and institutions... as well as journal editors and reviewers. In 2012 the European Association of Science Editors (EASE) established a gender policy committee to develop a set of standards for its adoption by scientific journals. The first purpose was to invite science editors to contribute to a survey of gender-equality policies in their journals, requesting information on gender balance, and its promotion among editorial staff, editorial boards and peer reviewers (http://www.apeer.org/). Health science researchers have gone into detail analysing how many women are involved in evaluating research results (http://www.eposters online.com/egs 2012/?q=node/38\&posterview=true \&first=true). In some fields they found that women are not reviewing in proportion 
to their own contributions. The most striking data they found is that in 2006, a highly ranked journal dedicated to neurophysiology had selected 30 times more men-only peer review panels than womenonly ones (Lane and Linden, 2009). They also concluded that peer review was not biased for this journal during that period. But the journal Nature has published so far several thematic issues and contributions dealing with this subject (http://www.nature.com/ nature/journal/v495/n7439/full/495047e.html), confirming that discrimination, even if it is unconscious, exists and that deep reflection is required now, followed by more research on the subject.

\section{Conclusions}

Although many claim that the h-index is, as at presently formulated, a useful summary measure of output and quality of researchers (Birks et al., 2014), this should be analysed carefully and critically to ensure that it is an effective tool when used to promote researchers and finance them with grants. The h-index is related not only to quality of contributions but also to quantity, especially citations.

In theory, absolute metrics of research performance, based on a combination of both quantity of research output and its quality or impact, are "objective" and should overcome these problems. But we, and others, have demonstrated that these metrics are seemed to be biased against female scientists (Symonds et al., 2006; Malakian et al., 2013). The Spanish system has registered $39 \%$ of female researchers, but only around $16 \%$ has reached the $h=10$ value to be included in the DIH database. A nearly similar number is found for earth science female researchers, meaning that they are less cited than men, leading to a much lower h-index. There are even some fields with no women at all in the list, as shown in Table 5. In Spain, a country that is leading the number of scientific female researchers in Europe (up to 39\%), the h-index is extremely low in all subdisciplines analysed in this article. Reflection on the results and conclusions obtained here should lead the different parties, from researchers to journal editors and reviewers to scientific policy makers, to consider and address this issue carefully.

A battery of actions should, in the view of the authors, be implemented, as a matter of priority, by all of those parties:

- A first step should be promoting and implementing the equal composition of editorial boards (McCook, 2013).

- Promotion of women as peer reviewers is another important step, both to cement the reputation of female contributions to science and to guarantee the unbiased process of peer reviewing. This would require Editors to proactively seek a gender balance on Editorial Boards.

- Networking of female scientists should be made more dynamic, requiring the inclusion of important collectives that are not currently represented in public listings (e.g. Spanish female earth scientists are absent from AcademiaNet, which is a database of profiles of leading female researchers from all disciplines: http://www.academia-net.org/). This will facilitate the networking among those scientists and the promotion of their research output leading to a higher citation of their work and therefore an increase in their h-index.

- Finally, although quotas are questioned by some (Vernos, 2013), measures to assure the presence of female researchers in all Editorial Boards, Grant Proposal Review panels and Governing Councils of learned societies should be considered. This will help validation of the contributions by female researchers and put these on an equal footing to those of males.

In this article we have aimed to raise awareness of the importance of gender equity composition of all publication processes including publication boards and peer reviewing systems to guarantee unbiased results. We recommend the wider consideration of these conclusions to better establish whether there is a real discrimination factor associated to the h-index based on the lower publication possibilities and citations based on that information.

The representation of scientific women in publication and research could be further explored by establishing which journals Spanish women researchers are submitting their papers to. It would be interesting to know if they submit to high IF journals or simply submit lower because they feel that they have a better chance of acceptance. This topic would be a demanding new piece of research since journals do not offer much information about rejected papers and, as far as we can establish, there are no data on the criteria used by women and by men to select the journals to which they submit papers.

Another issue to explore could be the comparison of male and female acceptance. It would be useful to identify representative samples of men and women and to examine the relative levels of acceptance and rejection for a sample of journals.

The next step could be to apply the same procedure in other research areas and in other countries where there is currently insufficient information on the subject. These lines of future work could enlarge the knowledge on the h-index for women scientists as, at present, their scientific careers are probably limited by "boiling down" all achievements to a single number h-index.

\section{Acknowledgements}

The authors are indebted to Brian Marker and Brian Pratt who had useful comments on this paper and helped in the final edition of the manuscript. Ana Alonso Zarza and Helena Henriques were very constructive in their review and we acknowledge their suggestions for improving the final result.

\section{References}

Alonso-Zarza, A. M., Álvarez-Marrón, J., Calonge, A., Díaz, C., Díez Balda, M.A., Gil Peña, I., and Gómez, M.I. 2008. Mujeres y Geología en España. Geotemas, v. 10, pp. 589.

Anderson Eloy, J., Svider, P., Chandrasekhar, S.S., Husain, Q., Mauro, K.M., Setzen, M., and Baredes, S. 2013. Gender Disparities in Scholarly Productivity within Academic Otolaryngology Departments. Otolaryngology, Head and Neck Surgery v. 148(2), pp. 215-222.

Arenzon, J.J., Duarte, P., Cavalcanti, S. and Barbosa, M.C. 2013. Women and physics in Brazil: Publications, citations and H-index, AIP Conf. Proc. 1517, 78. Available on line at http://dx.doi.org/10.1063/1.4794228

Bar-Ilan, J. 2008. Which h-index? A comparison of WoS, Scopus and Google Scholar, Scientometrics, v. 74(2), pp. 257-271.

Birks, Y., Fairhurst, C., Baird, W., Bloor, K.E., Campbell, M.K. and Torgerson, D.J. 2014. The use of the h-index to measure quality and output: A bibliometric analysis in health service research. Journal of Health Services Research \& Policy, v. 19(2), pp. 102-109.

Boletín Oficial del Estado, Ley Orgánica 3/2007 para la igualdad efectiva de mujeres y hombres. BOE-A-2007-6115, 2007, 59 pp.

MacPherson, A. 2015. Médicas de base, médicos al mando. Retrieved from http://www.lavanguardia.com/20150119/54423497784/ 
El-Hinnawi, E. 2015. Earth and Planetary Scientific Research in the World, Episodes March 2015, pp. 54-56.

European Commission 2013. She Figures 2012. Gender in Research and Innovation. Statistics and Indicators, Luxembourg.

Gonzales, L. 2010. Participation of women in geoscience occupations. Geoscience Currents, v. 33.

Harzing, A. W. 2008. Google Scholar - a new data source for citation analysis. Research in International Management. Retrieved from http:// www.harzing.com/pop_gs.htm

Hirsch J. E. 2005. An index to quantify an individual's scientific research output. Proceedings of the National Academy of Sciences of the United States of America, v. 102(46), pp. 16569-16572.

Jagsi, R, Guancial, E.A., Cooper Worobey, C., Henault, L.E., Chang, Y., Starr, R., Tarbell, N.J., and Hylek, E.M. 2006. The "gender gap" in authorship of medical literature. The New England Journal of Medicine v. 355, pp. 281-287.

Lane, J. A. and Linden, D. J. 2009. Is There Gender Bias in the Peer Review Process at Journal of Neurophysiology? Journal of Neurophysiology, v. 101(5), pp. 2195-2196.

Leydesdorff, L. 2008. Caveats for the Use of Citation Indicators in Research and Journal Evaluations.Journal of the American Society for Information Science and Technology, v. 59(2), pp. 278-287.

Maliniak, D., Powers, R. and Walter, B.F. (2013) The Gender Citation Gap in International Relations International Organization, v. 67(4), pp. 889-922.

McCook, A. 2013. Barred from the boardroom. Nature v. 495, pp. 25-27.

Ministerio de Economía y Competitividad 2014. Científicas en cifras 2013.Estadística e indicadores de la (des)igualdad de género en la

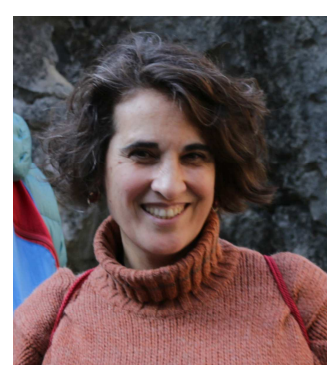

Dolores Pereira is professor of Geology and Engineering Geology at the University of Salamanca. She teaches as well at the Master of Social Studies for Science and Technology of this university. She is vicepresident of the IUGS Heritage Stone Task Group for southern Europe and Member of the network CONSTRUROCK. She is adviser and reviewer for UNESCO on World Heritage Sites. Her research interests include natural stones from their chemical, mineralogical, radiological and physico-mechanical characterization point of view as well as their use in new building and restoration of architectonic heritage. Dolores Pereira is member of the board of AMIT, the Spanish Association for Women in Science. formación y profesión investigadora.

Ministerio de Educación, Cultura y Deporte 2014. Datos y Cifras del Sistema Universitario Español.

Pashkova AA, Svider PF, Chang CY, Diaz L, Eloy JA, and Eloy JD. 2013. Gender disparity among US anaesthesiologists: are women under represented in academic ranks and scholarly productivity? Acta Anaesthesiol. Scand. v. 57(8), pp. 1058-64.

Pereira, D. 2014. Improving Female Participation in Professional Engineering Geology to Bring New Perspectives to Ethics in the Geosciences. Int. J. Environ. Res. Public Health 2014, v. 11(9), pp. 9429-9445.

Symonds, M.R.E., Gemmell, N.J., Braisher, T.L., Gorringe, K.L., and Elgar, M.A. 2006. Gender Differences in Publication Output: Towards an Unbiased Metric of Research Performance. PLoS ONE 1(1): e127. doi:10.1371/journal.pone.0000127

Vernos, I. 2013. Quotas are questionable, Nature v. 495, pp. 39.

Web pages cited:

http://www.academia-net.org/

http://www.apeer.org/

http://www.harzing.com/pop_hindex.htm

http://indice-h.webcindario.com/

http://www.lavanguardia.com/20150119/54423497784/

http://www.nature.com/nature/journal/v495/n7439/full/495047e.html

http://www.scopus.com/authid/detail.url?authorId=7401842667

http://www.uis.unesco.org/sciencetechnology/pages/women-in-science-leaky-

pipeline-data-viz.aspx

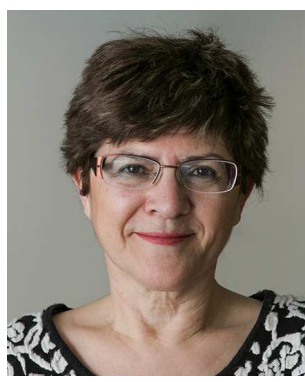

Capitolina Díaz is professor of Sociology at the University of Valencia (Spain) and President of the Spanish Association of Women in Science and Technology (AMIT). She teaches Sociology of Gender and Gender Relations, Science, Technology and Society. Main fields of research: Sociology of gender, Science and Gender and Gender globalization. Author of more than 90 papers, chapters and books. Researcher in 16 projects (national and international). She was part of the team who researched and wrote "Mapping the Maze: Getting more Women on the Top in Research" of the Directorate-General for Research EC. She was also member of the Helsinki Group for Women in Science from 2008 to 2010. 